\title{
Matrix Effect Assessment of an Ion Chromatographic Method to Determine Inorganic Anions in Wastewater
}

\author{
Rachel B. Costa $(\mathbb{D}$ - Priscila R. Camiloti • \\ Carolina A. Sabatini • Carla E. D. dos Santos • \\ Paulo C. F. Lima Gomes • Maria Ângela T. Adorno
}

Received: 25 February 2018 / Accepted: 1 June 2018 /Published online: 15 June 2018

(C) Springer International Publishing AG, part of Springer Nature 2018

\begin{abstract}
Inorganic anion monitoring is essential for bioreactor operation and is related for pollution control or energy and products recovery. However, there is a lack of studies validating methods for inorganic anions analyses in conditions compatible to those in bioreactor operations treating different types of wastewater. This paper provides a systematic statistical study and matrix-effect assessment for sugarcane vinasse, leachate, sewage and synthetic sewage. Sample preparation consisted of only a filtration and sample dilution. $\mathrm{Cl}^{-}, \mathrm{NO}_{2}{ }^{-}, \mathrm{NO}_{3}{ }^{-}, \mathrm{PO}_{4}{ }^{3-}$ and $\mathrm{SO}_{4}{ }^{2-}$ were determined in a Dionex ICS $5000 \AA$ equipped with a chemical conductivity suppressor. Calibration curves were linear and well-adjusted between 2.5 and $50 \mathrm{mg} \mathrm{L}^{-1}$ for all the anions in all the tested matrices, except $\mathrm{PO}_{4}{ }^{3-}$ and $\mathrm{SO}_{4}{ }^{2-}$ in vinasse. A calibration range for $\mathrm{PO}_{4}{ }^{3-}$ in all tested matrices was 5.0 to
\end{abstract}

R. B. Costa $(\bowtie) \cdot$ P. R. Camiloti · C. A. Sabatini •

C. E. D. dos Santos - M. Â. T. Adorno

Laboratory of Biological Processes, Center for Research,

Development and Innovations in Environmental Engineering, Sao

Carlos School of Engineering, University of Sao Paulo

(EESC/USP), Av. Joao Dagnone 1100, São Carlos, São Paulo

13563-120, Brazil

e-mail: rcbiancalana@gmail.com

M. Â. T. Adorno

e-mail: janja@sc.usp.br

P. C. F. Lima Gomes

Department of Analytical Chemistry, Sao Paulo State University,

UNESP, Araraquara, São Paulo 14800-970, Brazil
$100 \mathrm{mg} \mathrm{L}^{-1}$, whereas a range from $5.0 \mathrm{mg} \mathrm{L}^{-1}$ to $50 \mathrm{mg} \mathrm{L}{ }^{-1}$ was obtained for $\mathrm{SO}_{4}{ }^{2-}$ in vinasse. All the anions yielded recoveries in the range of $85-$ $115 \%$ for all the tested matrices. Relative standard deviations lower than 10 and $2 \%$ were achieved for peak areas and retention times, respectively. A signal enhancement was observed for all the tested matrices and all the anions. The matrix effect level varied from $-1.7\left(\mathrm{NO}_{2}{ }^{-}\right.$in vinasse $)$to $-33.9 \%\left(\mathrm{Cl}^{-}\right.$in leachate $)$. Sewage was the less affected matrix, while leachate gave higher matrix effects. Validation results and the matrix effect assessment showed that a simple sample preparation is suitable for multi-elemental analyses of inorganic anions for complex environmental samples.

Keywords Inorganic anion determination · Complex matrices $\cdot$ Standard addition method $\cdot$ Environmental chemistry

\section{Introduction}

Ion chromatography (IC) is a well-established method to analyse inorganic anions in water samples (Jackson 2006). By and large, IC is traditionally used for monitoring inorganic anion concentrations in water in order to ensure that environment samples present the quality standards required by legislation. The Environment Protection Agency (EPA) validated an IC method to analyse various anions in drinking water, surface water, groundwater, mixed domestic and industrial wastewaters (USEPA 1993). Since then, many papers have been 
published validating IC methodologies for different environmental samples, such as drinking water (Jackson et al. 1998; Miskaki et al. 2007; Lopez-Moreno et al. 2010), well-water (Lopez-Moreno et al. 2010), brines (Singh et al. 1996), high ionic water sample (Neele et al. 2002), coal mine and river water sample (Michalski et al. 2012).

A great deal of effort has gone into validating IC methods for inorganic anions in water, but there are few studies addressing different types of wastewater (Gade 1993; Jackson et al. 2001), and even in the EPA document, no further specification was presented regarding wastewater samples. In an extensive review, Michalski (2006) listed 67 studies in which IC was applied to anion determination in aqueous samples. Among these, only eight studies addressed IC use for wastewater characterisation, which is nearly $12 \%$ of the listed studies. Thus, IC is used for wastewater monitoring, but there is a lack of studies validating these methods for specific matrices. Validation and matrix-effect assessment studies are mandatory for wastewater applications, since these streams are complex regarding their chemical compositions.

Wastewaters can be classified as complex matrices, which are characterised by a high ionic strength and/or large disparities between analyte ion concentrations and other chemical species in the same sample (Paull and Nesterenko 2005). Due to its complexity, the matrix effect is likely to occur when analytical methods are used for wastewater. The matrix effect is broadly defined as the interference that other components other than the target analyte in the method response (Kruve et al. 2015). It is usually caused by compound co-elution with the analyte, which can either reduce or increase the response (signal suppression or signal enhancement, respectively) (Matuszewski et al. 2003; Kruve et al. 2015). There is a claim that IC is highly matrix independent (Neele et al. 2002), but the matrix effect in anion analyses using IC techniques was extensively investigated for cleaner matrices, such as drinking water and groundwater (Miskaki et al. 2007; Lopez-Moreno et al. 2010). Yet, to date, there are no studies addressing the matrix-effect in anion analyses using IC techniques adopted for wastewater samples.

Furthermore, validating IC methods used for wastewater needs to be reviewed to ensure that the method is still appropriate. On one hand, IC technology is being constantly modernised, with new generation suppressors, as well as high-selectivity and high-capacity columns (Michalski 2006). On the other hand, IC methods are usually used for wastewater characterisation or for environmental control purposes, and law requirements tend to become stricter. Additionally, other IC applications for monitoring anions have emerged from new technologies and prospects for wastewater treatment. Among these, the biorefinery approach is gaining attention. According to this proposal, wastewater treatment plants can be considered as an industry, which is able to transform sustainable organic waste management into a spectrum of marketable products (Poggi-Varaldo et al. 2014). Given this context, monitoring anions is an important parameter for operating biological reactors treating wastewater, as some anions in excess, such as nitrite, can be toxic to microorganisms or can interfere in the target processes (Philips et al. 2002). High concentrations of sulphate, for example, could impair energy generation (methanogenesis) when sugarcane vinasse is used as feedstock (Kiyuna et al. 2017). Another approach of applying IC to wastewater is related to the possibility of nutrient recovery, such as phosphate (García et al. 2017) and elemental sulphur (Camiloti et al. 2016). Hence, it is critical to validate the IC method to analyse inorganic anions in conditions compatible to those in biological reactor operations.

Besides the compatibility of using the method with the samples conditions, it is highly desirable for analytical methods to be carried out quickly, adopting simple and automated sample pre-treatment procedures. These characteristics aim to save operator labour and time, and also minimise reagents and material wasted (LopezMoreno et al. 2010). Moreover, in the case of complex matrices, it is desirable for the accuracy of the method to be improved, taking into account matrix effects, widely recognised as an important source of error when analysing environmental samples. One of the advantages of using IC for inorganic anion determination is that it provides a simultaneous multi-elemental analysis, minimising the time required for the measurements (Michalski 2006). Nevertheless, environmental samples are usually considered too difficult to deal with, requiring complex pre-treatment steps (Jackson 2006). Technological advances in IC equipment, such as precolumns (Michalski 2006), tend to minimise sample pre-treatment requirements and increase method accuracy. In this paper, sample preparation consisted of prefiltration and dilution.

So far, IC application, method validation, and matrixeffect assessment for complex environmental matrices, 
such as sugarcane vinasse, leachate, domestic and synthetic sewage, have not yet been examined in depth. In this paper, we studied the analyses of chloride, nitrite, nitrate, phosphate and sulphate in domestic wastewater, synthetic sewage (common substrates used for research purposes), sugarcane vinasse and leachate in an IC system equipped with a last generation chemical conductivity suppressor. Therefore, the main contribution of this paper is the systematic statistical study and matrix-effect assessment carried out for five inorganic anions in different wastewaters matrices submitted to simple pre-treatment.

\section{Material and Methods}

\subsection{Instruments}

A Dionex ICS 5000® (California, USA) system consisting of an AG23 guard column $(4 \times 50 \mathrm{~mm})$, an AS $23(4 \times 250 \mathrm{~mm})$ analytical column, a selfregeneration chemical suppression system, and a conductivity detector was used. The chemical suppression device was AERS $5004 \mathrm{~mm}$, and its current was set at $25 \mathrm{~mA}$, while the conductivity detector was a CD20. The column temperature was set at $35^{\circ} \mathrm{C}$, and the conductivity detector was $30^{\circ} \mathrm{C}$.

Injection was made through an AS autosampler device, and the injection loop volume was set at $10 \mu \mathrm{L}$. All parts of the IC, such as the injection valve, high-pressure pump, conductivity detector, suppressor module, peristaltic pump and autosampler were fully controlled by the Chromeleon Chromatography Management 7.1 program.

Isocratic elution (at a flow rate of $1.0 \mathrm{~mL} \mathrm{~min}^{-1}$ ) was used, and an analytical grade (>99\%) sodium carbonate (Aldrich) and sodium hydrogen carbonate (Sigma-Aldrich-Steinheim, Germany) were diluted in ultrapurified water to prepare the eluent at a concentration of 4.5 and $0.8 \mathrm{mM}$, respectively.

\subsection{Chemicals}

All the chemicals included in this study were purchased at an analytical grade (purity $>99 \%$ ). Sodium chloride $(\mathrm{NaCl})$ and sodium sulphate $\left(\mathrm{Na}_{2} \mathrm{SO}_{4}\right)$ were acquired from Sigma-Aldrich (Steinheim, Germany), while sodium nitrite $\left(\mathrm{NaNO}_{2}\right)$, sodium nitrate $\left(\mathrm{NaNO}_{3}\right)$ and potassium phosphate dibasic $\left(\mathrm{K}_{2} \mathrm{HPO}_{4}\right)$ were acquired from
Mallinckodt Backer (New Jersey, USA). The water used was ultrapurified with a Milli-Q water purification system from Millipore (Bedford, MA, USA), which conductivity was $0.6 \mu \mathrm{S}$.

\subsection{Sample Preparation}

Individual standard stock solutions $\left(1000 \mathrm{mg} \mathrm{L}^{-1}\right)$ were prepared in deionised water and stored at $4{ }^{\circ} \mathrm{C}$ in the dark for a maximum of 3 days. Calibration standard solutions were prepared both in water and in the matrix at seven concentration levels: 2.5, 5.0, 10.0, 20.0, 40.0 and $50.0 \mathrm{mg} \mathrm{L}^{-1}$ (chloride, nitrite, nitrate and sulphate) and 5.0, 10.0, 20.0, 40.0 and 100.0 $\mathrm{mg} \mathrm{L}^{-1}$ (phosphate). Calibration standard solutions were prepared by independent dilution from the standard stock solution. Two types of control samples were analysed: Blank samples were constituted by ultra-purified water, while the "zero" concentration level refers to matrix samples in which no standard solution was spiked. Four matrices were tested as follows:

1. Synthetic complex wastewater that mimics sewage. This lab-made wastewater is often used for research purposes since it does not present composition variation. The sample was prepared as described by Camiloti et al. (2013).

2. Domestic sewage was collected at the entrance of the wastewater treatment plant from the neighbourhood near Campus 2 at the University of São Paulo (EESC/USP).

3. Sugarcane vinasse, which is a by-product of ethanol production, rich in carbohydrates (COD may be 100 -fold higher than in sewage) and in sulphate (Fuess and Garcia 2015). Sugarcane vinasse sample was collected from a distillery in Brazil centre-south region (Sao Martinho distillery) during the 2015/ 2016 harvest. Sugarcane vinasse was kept refrigerated at $4 \pm 2{ }^{\circ} \mathrm{C}$.

4. Solid waste leachate: the sample was collected from a deactivated landfill $\left(21^{\circ} 57^{\prime} \mathrm{S}\right.$ and $\left.47^{\circ} 55^{\prime} \mathrm{W}\right)$ in São Carlos, São Paulo (Brazil), in March 2016. Sampling was made from the leachate lagoon.

The mentioned matrices are used in biological reactors for treatment and have high ionic strength (Table 1) that could influence anion determination by ion chromatography (Jackson et al. 2001; Jackson 2006). To evaluate the interferences of the analytes contained in 
the four different matrices used in this study, calibration curves were built for each of them. Besides inorganic anion profile, chemical organic demand (COD) was also assessed for the matrices following the spectrophotometric method (APHA 2005). Electrical conductivity was determined with the aid of a Digimed DM-31 conductivity electrode. COD concentration and the electrical conductivity of each tested matrix are presented in Table 1.

Matrix samples were prepared by spiking standard solutions in the matrix. The standard calibration volume varied according to the concentration level, and the matrix volume spiked varied according to the dilution rate applied for each matrix.

Synthetic wastewater and sewage were diluted 10 times, while a 100-time dilution rate was applied to sugarcane vinasse and solid waste leachate. The unique sample preparation procedure consisted of filtering samples in a $1.2-\mu \mathrm{m}$ glass fibre membrane followed by a $0.22 \mu \mathrm{m}$ cellulose acetate membrane. To conduct the same procedure in all cases, a single Chromafil ${ }^{\circledR} \mathrm{GF} /$ PET (Macherey-Nagel, GE) syringe filter was used for each sample and all the samples were filtered (including those in ultra-purified water) (Jackson 2006).

\subsection{Validation Study}

The performance characteristics studied were linearity, detection/quantification limits, recovery, precision (repeatability) and the matrix effect. Resolution and asymmetry were also evaluated according to the European Pharmacopoeia (EP) calculations.

\subsubsection{Detection and Quantification Limits}

A visual method was used to assess the limit of detection (LOD). Different known concentrations were added to deionised water. The lower concentration, which gave a visually observed response, was considered the minimum level at which the analyte could be reliably detected (Thompson et al. 2002; Araujo 2009; Kruve et al. 2015). The tested concentrations were $0.2,0.5,1.0,2.5$ and $5.0 \mathrm{mg} \mathrm{L}^{-1}$ for all the tested anions. Each concentration level was injected in triplicate.

The limit of quantification (LOQ) was defined as the lowest concentration measured with a confidence degree that was systematically measured. Relative standard deviation regarding a peak area lower or equal to 10\% (Thompson et al. 2002; Lopez-Moreno et al. 2010) and $2 \%$, regarding retention time, was adopted as the confidence degree (Villagrán et al. 2004).

\subsubsection{Linearity}

The linearity of the response was studied by using matrix-matched calibration solutions prepared by spiking standard stock extracts at seven concentration levels for all the five matrices. Concentration levels ranged

Table 1 Physicochemical characterisation of the tested matrices

\begin{tabular}{|c|c|c|c|c|}
\hline \multirow[b]{2}{*}{ Parameters } & \multicolumn{4}{|l|}{ Tested matrices } \\
\hline & Synthetic wastewater & Sewage & Sugar cane vinasse & Solid waste leachate \\
\hline $\mathrm{COD}\left(m g \mathrm{O}_{2} L^{-1}\right)$ & $436.1 \pm 32.3$ & $564.3 \pm 35.7$ & $32,640.0 \pm 255.0$ & $1519.0 \pm 76.0$ \\
\hline Electrical conductivity $\left(\mathrm{mS} \mathrm{cm}^{-1}\right)$ & 0.8 & 0.6 & 13.6 & 8.8 \\
\hline $\mathrm{pH}$ & $7.5-7.9$ & $7.0-8.0$ & $3.7-4.6$ & $7.4-7.7$ \\
\hline Chloride $\left(\mathrm{mg} \mathrm{L}^{-1}\right)$ & $30-160$ & $\sim 0.0$ & $59.4-1219.0$ & $230.0-2305.0$ \\
\hline Nitrite $\left(\mathrm{mg} \mathrm{L}^{-1}\right)$ & 0.0 & 0.0 & 0.0 & 0.0 \\
\hline Nitrate $\left(\mathrm{mg} \mathrm{L}^{-1}\right)$ & $4.2-4.6$ & $0-2$ & 0.0 & $22.4-35.1$ \\
\hline Phosphate (mg L ${ }^{-1}$ ) & $8.0-10.2$ & $3.0-9.0$ & & \\
\hline Sulphate $\left(\mathrm{mg} \mathrm{L}^{-1}\right)$ & 0.0 & & $200-1400$ & $7-42$ \\
\hline Alkalinity $\left(\mathrm{mg} \mathrm{CaCO}_{3} \mathrm{~L}^{-1}\right)$ & $592.0-620.0$ & $100.0-200.0$ & 0.0 & $3670.0-11,200.0$ \\
\hline References & $\begin{array}{l}\text { Chiu et al. (2007) } \\
\text { Moura et al. (2012) }\end{array}$ & $\begin{array}{l}\text { Tchobanoglous et al. (2003) } \\
\text { Von Sperling (2007) }\end{array}$ & $\begin{array}{l}\text { Moraes et al. (2015) } \\
\text { Christofoletti et al.(2013) } \\
\text { Fuess and Garcia (2015) } \\
\text { Dos Santos et al. (2013) }\end{array}$ & $\begin{array}{l}\text { Kjeldsen et al. (2002) } \\
\text { Lacerda et al. (2014) } \\
\text { Naveen et al. (2016) }\end{array}$ \\
\hline
\end{tabular}

COD and electrical conductivity were obtained by direct measurements (italic) 
from 2.5 to $50 \mathrm{mg} \mathrm{L}^{-1}$ for the anions, except phosphate, whose levels ranged from 5.0 to $100 \mathrm{mg} \mathrm{L}^{-1}$. Different concentration levels were injected randomly, but each matrix was injected into a separate batch. Calibration curves were prepared in triplicate, and matrice samples with no analyte addition were also analysed in triplicate. A blank (i.e., ultra-purified water) was injected at every 10 samples to ensure no occurrence of a carry-over effect.

Calibration curves were determined using the least squares method. The significance of linearity was assessed through the analysis of variance (test $F$ ) and the lack of adjustment test. Calibration curves were considered linear when linearity was significant $(F>$ $\left.F_{\text {critical }}\right)$ and lack of adjustment was non-significant $(F<$ $F_{\text {critical }}$ ) for a significance level of $95 \%$ (Villagrán et al. 2004). The coefficient of determination $\left(r^{2}\right)$ was also calculated as the quotient $\mathrm{SQ}_{\mathrm{reg}} / \mathrm{SQ}_{\mathrm{t}}$.

\subsubsection{Recovery}

Recovery studies were determined in all investigated matrices, i.e., synthetic sewage, domestic wastewater, vinasse and leachate. The samples were spiked with the analytes at three concentration levels-2.5, 20.0 and $50.0 \mathrm{mg} \mathrm{L}^{-1}$ - and three replicates for the "blank" sample and spiked sample $(n=12)$ for each matrix were performed.

The standard addition method was used for three matrices: domestic wastewater (chloride), sugarcane vinasse (chloride and sulphate) and solid waste leachate (chloride and sulphate). The standard addition is used when the sample contains the analyte of interest (Miller and Miller 2010). The recovery was calculated by Eq. 1 and the recovery by standard addition was calculated by Eq. 2. An acceptable recovery should fall between 85 and 115\% (USEPA 1993; Villagrán et al. 2004).

$$
R(\%)=\frac{\text { measured concentration }}{\text { theoretical concentration }} \times 100
$$

$$
R_{s a}(\%)=\frac{\text { measured concentration-blank }}{\text { added concentration }} \times 100
$$

\subsubsection{Precision and Sample Stability}

Chromatographic method precision was determined as the relative standard deviation (RSD), obtained from injected triplicates of spiked matrices during the same day (repeatability). RSD was calculated for the peak area and retention time.

The samples were kept in the auto sampler and were injected at 2, 4, 6, 8, 12 and $24 \mathrm{~h}$ to evaluate the injector stability. Storage stability was studied at $-20{ }^{\circ} \mathrm{C}$. A sample in the medium level of the curve range was injected after being subjected to freezing and defreezing after 2, 4, 6, 8, 12 and $24 \mathrm{~h}$. Injector and storage stabilities were assessed only for deionised water.
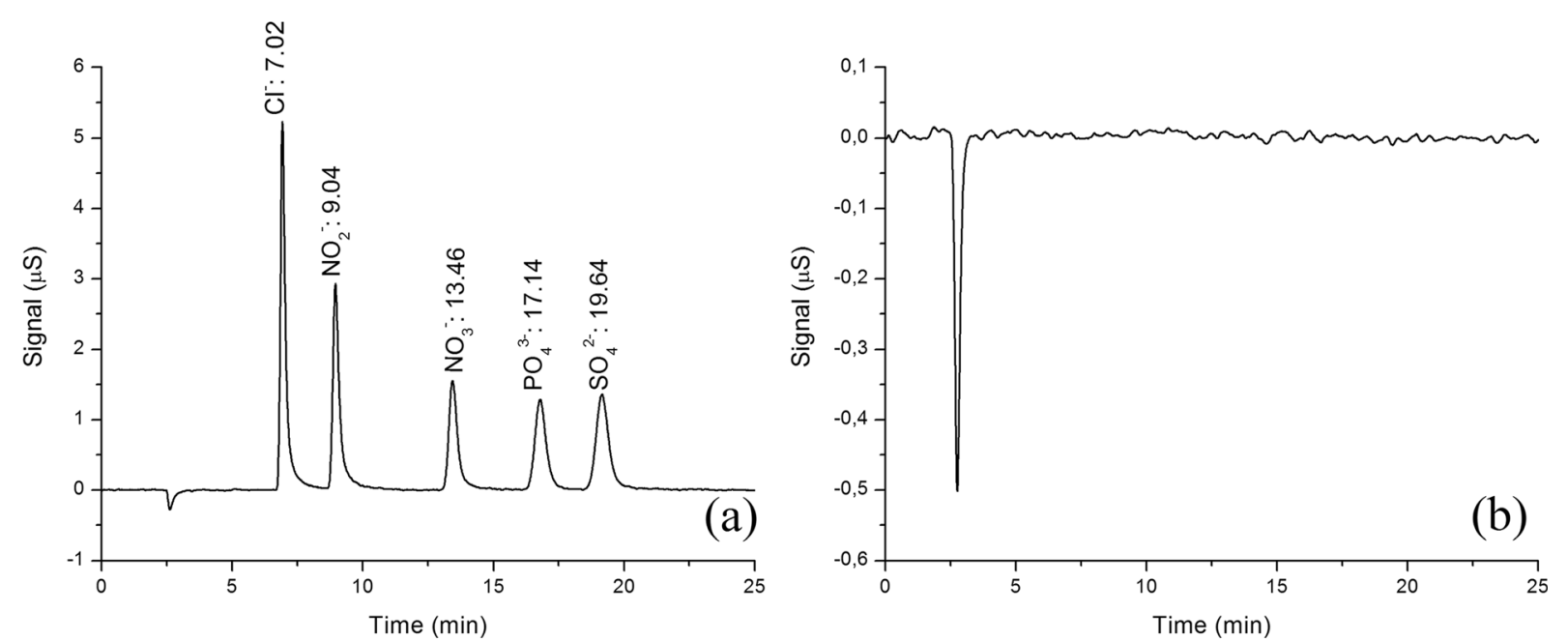

Fig. 1 a Typical chromatogram for the target anions. b Typical chromatogram obtained for a blank sample 
Table 2 Retention times ( $\mathrm{min}$ ) of the target anions in the investigated matrices

\begin{tabular}{|c|c|c|c|c|c|}
\hline & Chloride & Nitrite & Nitrate & Phosphate & Sulphate \\
\hline Water & $7.02 \pm 0.01$ & $9.04 \pm 0.01$ & $13.46 \pm 0.02$ & $17.14 \pm 0.03$ & $19.64 \pm 0.04$ \\
\hline Synthetic sewage & $7.01 \pm 0.01$ & $9.01 \pm 0.01$ & $13.42 \pm 0.03$ & $17.06 \pm 0.03$ & $19.52 \pm 0.02$ \\
\hline Domestic wastewater & $7.00 \pm 0.02$ & $9.00 \pm 0.01$ & $13.40 \pm 0.02$ & $17.03 \pm 0.02$ & $19.49 \pm 0.03$ \\
\hline Vinasse & $7.01 \pm 0.01$ & $9.02 \pm 0.01$ & $13.45 \pm 0.04$ & $17.11 \pm 0.05$ & $19.59 \pm 0.03$ \\
\hline Leachate & $7.00 \pm 0.02$ & $9.00 \pm 0.01$ & $13.39 \pm 0.03$ & $17.01 \pm 0.04$ & $19.47 \pm 0.03$ \\
\hline
\end{tabular}

\subsubsection{Matrix Effect}

The matrix effect assessment was made by comparing the slopes of the analytical curves prepared in matrix and in ultra-purified water, represented by the percentage of signal enhancement or suppression
$(\mathrm{C}(\%))$. The matrix effect was considered low when between the range of $-20 \%<\mathrm{C}(\%)<20 \%$, medium for the range $-50 \%<\mathrm{C}(\%)<-20 \%$ or $20 \%>\mathrm{C}$ $(\%)>50 \%$ and high when lower than $-50 \%(\mathrm{C}(\%)$ $<-50)$ or higher than $50(\mathrm{C}(\%)>50)$ (Economou et al. 2009).
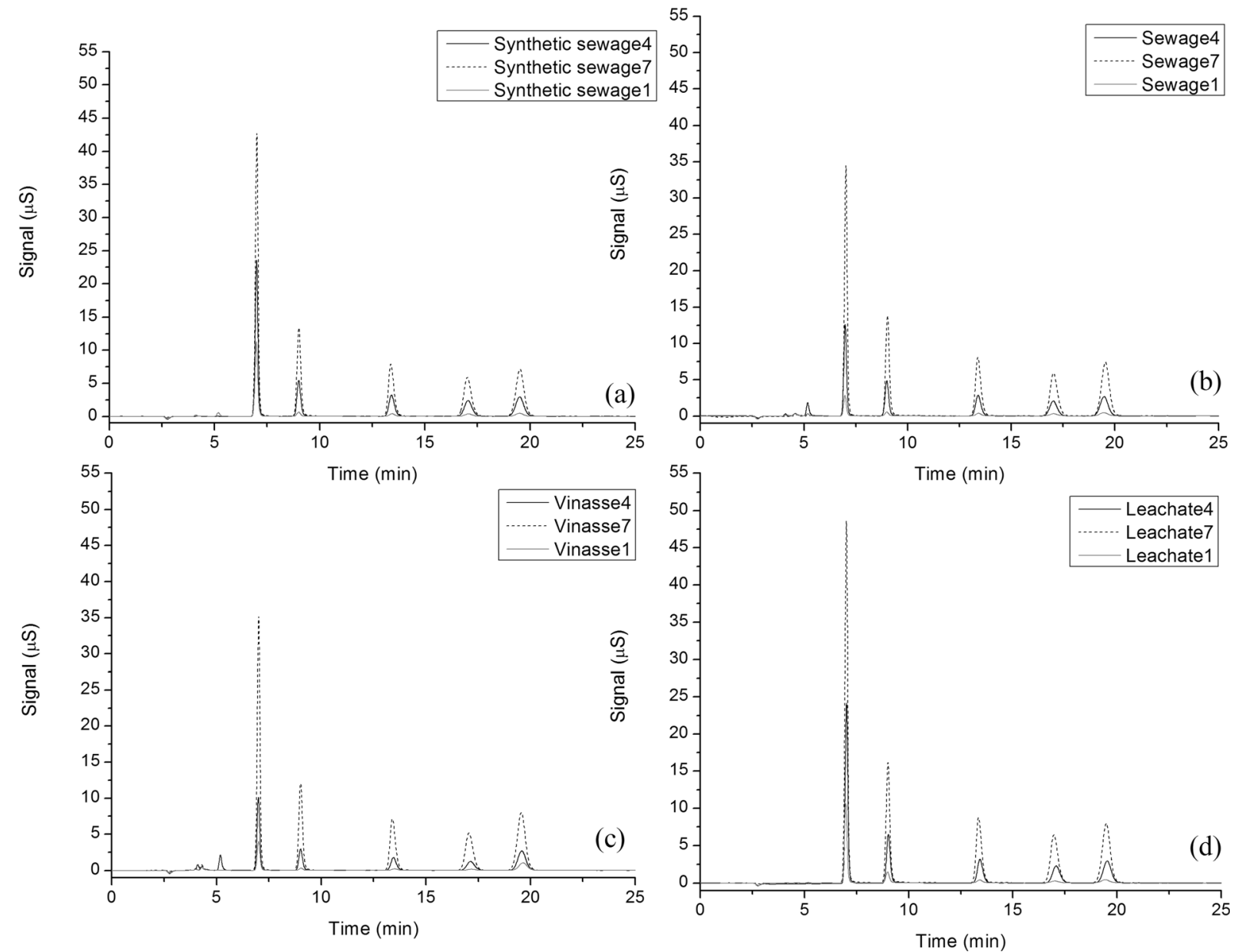

Fig. 2 Chromatograms obtained for a synthetic sewage, b sewage, $\mathbf{c}$ vinasse and $\mathbf{d}$ leachate. The chromatograms were obtained at low (1), medium (4) and high (7) level concentrations. Low,

medium and high range levels correspond to 5.0, 40.0 and $100.0 \mathrm{mg} \mathrm{L}^{-1}$ for phosphate. For the other anions, range levels are 2.5 (low), 20 (medium) and 50 (high) $\mathrm{mg} \mathrm{L}^{-1}$ 


\section{Results and Discussion}

A typical chromatogram obtained in ultra-purified water is shown in Fig. 1. The retention times for the peaks of interest in all the five investigated matrices are shown in Table 2. Average resolution and asymmetry were 6.69 and 1.14 (EP), respectively. We did not observe distortion of the baseline in the concentration range tested. The chromatograms observed in high ionic matrices, fortified with higher anion concentration, were characterised by good resolution (Fig. 2). Neither resolution decline nor peaks broadening were observed in samples with high anion concentration. These effects were previously reported (Neele et al. 2002) as related to high ionic strength matrices in IC but were not observed in the wastewater matrices tested. This difference could be due to the exchange capacity of the columns.

\subsection{Limits of Detection and Quantification}

LOD obtained according to the visual method was $0.5 \mathrm{mg} \mathrm{L}^{-1}$ for chloride, nitrite, nitrate and sulphate (Fig. 3a, b). For phosphate, the LOD was $2.5 \mathrm{mg} \mathrm{L}^{-1}$ (Fig. 3c).

LOQ obtained with RSD $\leq 10 \%$ for the peak and $\leq$ $2 \%$ retention time shift were $2.5 \mathrm{mg} \mathrm{L}^{-1}$ for chloride, nitrate, nitrite and sulphate, and $5.0 \mathrm{mg} \mathrm{L}^{-1}$ for phosphate (Fig. 3d).

Both LOD and LOQ obtained by visual method are higher than those described elsewhere (USEPA 1993; Neele et al. 2002; Lopez-Moreno et al. 2010). However, these authors calculated the LOD and LOQ by multiplying the standard deviation of the lower standard by 3 (to obtain LOD) or 10 (to obtain LOQ). Neither of them utilised the visual method, which gives a stricter
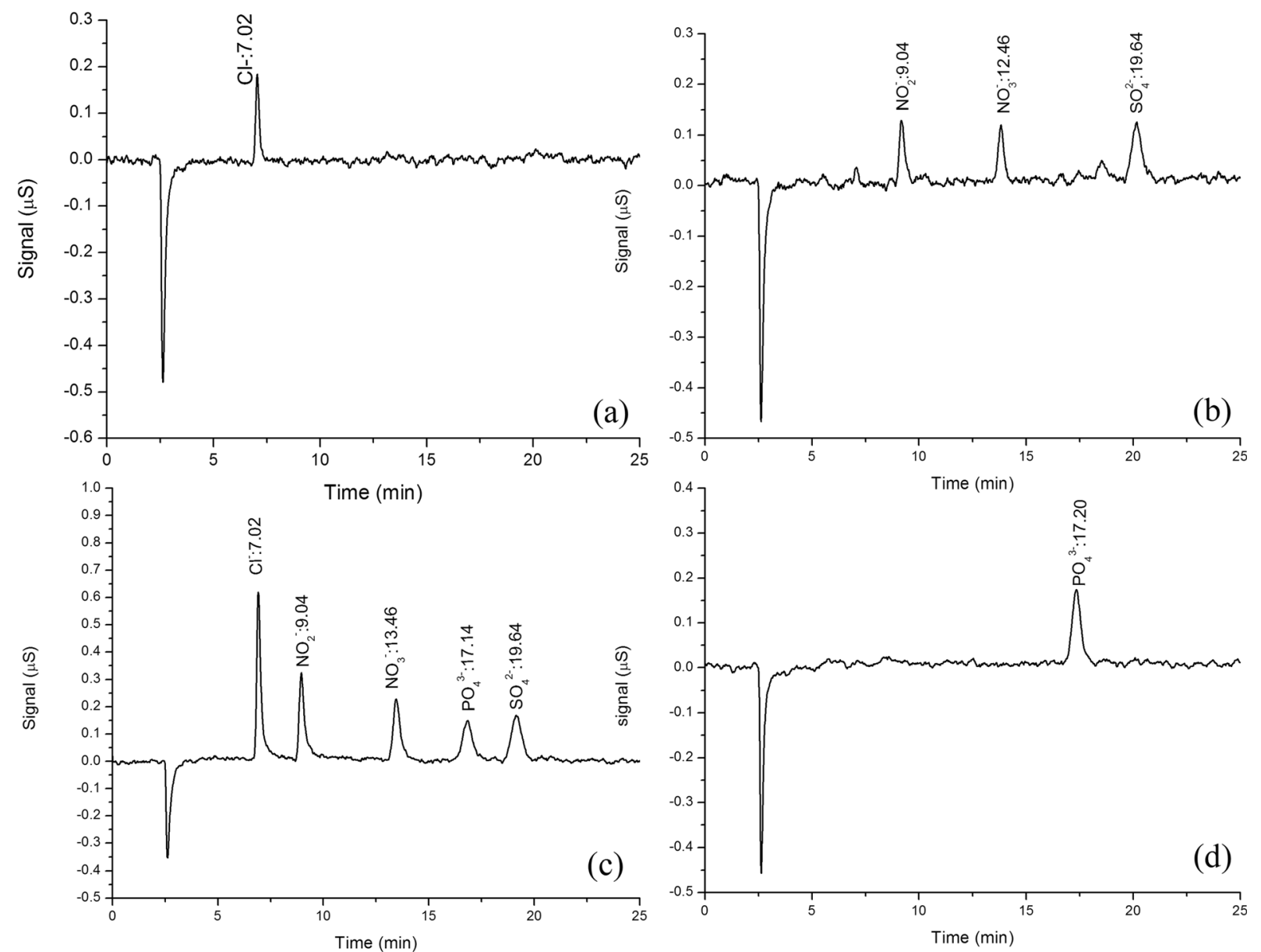

Fig. 3 Chromatograms obtained at LOD and LOQ concentrations of a $0.5 \mathrm{mg} \mathrm{L}^{-\mathbf{1}}$ (LOD) for $\mathrm{Cl}^{-}, \mathbf{b} 0.5 \mathrm{mg} \mathrm{L}^{-1}$ (LOD) for NO${ }_{2}^{-}, \mathrm{NO}_{3}{ }^{-}$and $\mathrm{SO}_{4}{ }^{2-}$, c $2.5 \mathrm{mg} \mathrm{L}^{-1} \mathrm{LOQ}$ for $\mathrm{Cl}^{-}, \mathrm{NO}_{2}{ }^{-}, \mathrm{NO}_{3}{ }^{-}$and $\mathrm{SO}_{4}{ }^{2-}$ and $\mathrm{LOD}$ for $\mathrm{PO}_{4}{ }^{3-}$, and $\mathbf{d} 5.0 \mathrm{mg} \mathrm{L}{ }^{-1}$ (LOQ) for $\mathrm{PO}_{4}{ }^{3-}$ 
response. Additionally, EPA (1993) and Neele et al. (2002) used analytical columns characterised by low exchange capacity $\left(20 \mu \mathrm{eq} \mathrm{L}^{-1}\right)$.

\subsubsection{Linearity}

Calibration curves in water were linear for all anions tested in the range of $2.5-50.0 \mathrm{mg} \mathrm{L}^{-1}$ for $\mathrm{Cl}^{-}, \mathrm{NO}_{2}{ }^{-}$, $\mathrm{NO}_{3}{ }^{-}$and $\mathrm{SO}_{4}{ }^{2-}$. Interval calibration range for $\mathrm{PO}_{4}{ }^{3-}$ went from 5.0 to $100 \mathrm{mg} \mathrm{L}^{-1}$. This range is compatible with the range presented by Michalski et al. (2012), who utilised an analytical column whose capacity was $210 \mu \mathrm{eq} \mathrm{L}^{-1}$, and applied IC for coal mine water and for a water river samples highly contaminated with industrial waste. Hence, obtaining linear calibration curves in $2.5-50 \mathrm{mg} \mathrm{L}^{-1}$ is convenient for inorganic anions analyses in wastewater samples.

For sewage, synthetic sewage and leachate calibration curves were linear in the same range as water. In vinasse samples, calibration curves were linear in the range of $5.0-50 \mathrm{mg} \mathrm{L}^{-1}$ for chloride and sulphate, probably due to the high concentrations of such anions in the matrix. For the other anions (nitrite, nitrate and phosphate), calibration curves were linear in the same range described for water ( 2.5 to $50 \mathrm{mg} \mathrm{L}^{-1}$ for nitrite and nitrate or 5.0 to $50 \mathrm{mg} \mathrm{L}^{-1}$ for phosphate). ANOVA showed that the analyte calibration curves presented linearity in all matrices with well-adjusted models without lack-of-fit (Table 3).

Table 3 Linearity and lack of adjustment tests for $\mathrm{Cl}^{-}, \mathrm{NO}_{2}{ }^{-}, \mathrm{NO}_{3}{ }^{-}, \mathrm{PO}_{4}{ }^{3-}$ and $\mathrm{SO}_{4}{ }^{2-}$ for five different matrices

\begin{tabular}{|c|c|c|c|c|c|c|c|}
\hline & & \multirow[t]{2}{*}{ Curve } & \multirow[t]{2}{*}{$r^{2}$} & \multicolumn{2}{|c|}{ Linearity test } & \multicolumn{2}{|c|}{ Lack of adjustment test } \\
\hline & & & & $F$ & Ftab & $F$ & Ftab \\
\hline \multirow[t]{5}{*}{ Chloride } & Water & $0.08647 x-0.06405$ & 0.9909 & 1643.9 & 4.6 & 2.3 & 3.5 \\
\hline & Sewage & $0.09278 x+0.2058$ & 0.9839 & 1340.8 & 4.3 & 2.6 & 2.8 \\
\hline & Synthetic sewage & $0.10952 x+1.3811$ & 0.9935 & 3367.8 & 4.3 & 1.6 & 2.7 \\
\hline & Vinasse $(*)$ & $0.0966 x+0.7812$ & 0.9964 & 4200.8 & 4.5 & 1.9 & 3.3 \\
\hline & Leachate & $0.11567 x+1.5268$ & 0.9924 & 2758.2 & 4.3 & 2.2 & 2.8 \\
\hline \multirow[t]{5}{*}{ Nitrite } & Water & $0.05244 x-0.0442$ & 0.9827 & 1568.4 & 4.5 & 2.7 & 3.2 \\
\hline & Sewage & $0.05495 x-0.0428$ & 0.9878 & 1555.1 & 4.4 & 2.2 & 3.0 \\
\hline & Synthetic sewage & $0.05915 x-0.415$ & 0.9939 & 6209.5 & 4.4 & 1.6 & 3.0 \\
\hline & Vinasse & $0.053 x-0.0433$ & 0.9940 & $11,201.1$ & 4.4 & 2.0 & 3.0 \\
\hline & Leachate & $0.0633 x+0.1699$ & 0.9930 & 6517.7 & 4.3 & 2.4 & 2.7 \\
\hline \multirow[t]{5}{*}{ Nitrate } & Water & $0.0450 x-0.0194$ & 0.9902 & 1408.6 & 4.6 & 3.0 & 3.5 \\
\hline & Sewage & $0.04654 x-0.0238$ & 0.9876 & 1507.2 & 4.4 & 2.2 & 3.0 \\
\hline & Synthetic sewage & $0.0507 x-0.0247$ & 0.9935 & 5818.4 & 4.4 & 1.6 & 3.0 \\
\hline & Vinasse & $0.04616 x-0.0381$ & 0.9981 & 9447.4 & 4.4 & 1.6 & 3.0 \\
\hline & Leachate & $0.05381 x-0.0382$ & 0.9955 & 6695.7 & 4.5 & 1.7 & 3.3 \\
\hline \multirow[t]{5}{*}{ Phosphate } & Water & $0.02205 x-0.0245$ & 0.9869 & 1119.0 & 4.5 & 1.8 & 3.3 \\
\hline & Sewage & $0.02318 x+0.0054$ & 0.9782 & 1978.7 & 4.3 & 1.2 & 2.7 \\
\hline & Synthetic sewage & $0.02565 x+0.0053$ & 0.9941 & 7381.1 & 4.3 & 1.9 & 2.7 \\
\hline & Vinasse & $0.02308 x-0.0336$ & 0.9982 & $10,190.4$ & 4.4 & 1.4 & 3.2 \\
\hline & Leachate & $0.02707 x-0.0465$ & 0.9964 & 4880.4 & 4.4 & 2.4 & 3.2 \\
\hline \multirow[t]{5}{*}{ Sulphate } & Water & $0.05947 x-0.0228$ & 0.9861 & 2136.5 & 4.5 & 2.2 & 3.3 \\
\hline & Sewage & $0.06112 x+0.0503$ & 0.9888 & 1955.6 & 4.3 & 1.7 & 2.7 \\
\hline & Synthetic sewage & $0.06659 x+0.0174$ & 0.9943 & 7753.0 & 4.3 & 1.8 & 2.7 \\
\hline & Vinasse(*) & $0.06288 x+0.6417$ & 0.9965 & 4365.0 & 4.5 & 2.0 & 3.4 \\
\hline & Leachate & $0.06980 x+0.0338$ & 0.9948 & 7749.5 & 4.3 & 2.1 & 2.8 \\
\hline
\end{tabular}

*Calibration curve range from 5.0 to $50 \mathrm{mg} \mathrm{L}^{-1}$ 


\subsubsection{Recovery}

Recovery was assessed in low-, medium- and highrange levels. Table 4 shows trueness calculated for each of the tested matrices. All the target anions yielded recoveries in the range of $85-115 \%$ for all tested matrices in the three range levels of the calibration curve. The highest recovery was observed for nitrite in domestic sewage in low level concentration (114\%). Nitrite in low level concentration was also the anion for which we observed the worst recovery- $91 \%$ in vinasse calibration curve. Nitrite, nitrate and phosphate in vinasse were the anions which yielded the lowest recoveries, compared with the same parameter in other matrices. Recoveries for chloride and nitrate in low level concentration for water are higher than expected. Since the calibration curve in water was prepared in ultrapure water, without any compound, it was expected recoveries to be nearer to $100 \%$. Carry over effect could explain higher recoveries, but this effect was not seen in any blank sample injected during the validation procedures. Besides, phosphate and sulphate recoveries are in the expected range for low-level concentration in water. Nevertheless, chloride and nitrate recoveries are within the acceptable range (USEPA 1993; Villagrán et al. 2004).

\subsubsection{Precision}

Method repeatability was evaluated as relative standard deviation (RSD) at three different levels of the range (low, medium and high). Precision was assessed for the peak area (Table 5) and for retention time (Table 6). It can be observed in Table 5 that the RSD of peak areas were lower than $10 \%$ for all the target anions in all the five matrices. In case of water samples, higher RSD was observed in medium level concentration for chloride, nitrite, nitrate and sulphate, but higher RSD was expected for low level concentration. Regarding the other matrices, higher RSD was observed in low level for all tested concentrations only in leachate. No trend was observed in RSD for the other matrices. Nonetheless, RSD of peak areas was lower than $10 \%$ for all the target anions in all the five matrices. Therefore, precision regarding peak areas is within the range recommended by Thompson et al. (2002), which indicates that this method fits for inorganic anion analyses in different types of wastewater samples.

A typical interference observed in IC is ionic character displacement (USEPA 1993). It occurs when
Table 4 Recoveries of $\mathrm{Cl}^{-}, \mathrm{NO}_{2}{ }^{-}, \mathrm{NO}_{3}{ }^{-}, \mathrm{PO}_{4}{ }^{3-}$ and $\mathrm{SO}_{4}{ }^{2-}$ in five different samples

\begin{tabular}{|c|c|c|c|c|}
\hline \multirow[t]{2}{*}{ Matrix } & \multirow[t]{2}{*}{ Anion } & \multicolumn{3}{|c|}{ Recovery } \\
\hline & & Low & Medium & High \\
\hline \multirow[t]{5}{*}{ Water } & Chloride & 112.5 & 98.2 & 102.1 \\
\hline & Nitrite & 104.8 & 97.8 & 106.2 \\
\hline & Nitrate & 107.2 & 101.5 & 103.0 \\
\hline & Phosphate & 98.9 & 105.7 & 97.0 \\
\hline & Sulphate & 99.3 & 101.2 & 97.3 \\
\hline \multirow[t]{5}{*}{ Synthetic sewage } & Chloride & 103.6 & 103.5 & 100.1 \\
\hline & Nitrite & 103.0 & 101.4 & 100.3 \\
\hline & Nitrate & 103.8 & 101.6 & 100.4 \\
\hline & Phosphate & 111.5 & 101.0 & 100.9 \\
\hline & Sulphate & 108.3 & 101.4 & 100.5 \\
\hline \multirow[t]{5}{*}{ Domestic wastewater } & Chloride & 103.3 & 99.1 & 103.4 \\
\hline & Nitrite & 113.7 & 99.8 & 102.2 \\
\hline & Nitrate & 102.4 & 100.5 & 102.0 \\
\hline & Phosphate & 108.3 & 101.4 & 100.5 \\
\hline & Sulphate & 112.7 & 99.7 & 101.8 \\
\hline \multirow[t]{5}{*}{ Vinasse } & Chloride & 106.4 & 93.6 & 99.9 \\
\hline & Nitrite & 90.8 & 96.2 & 99.8 \\
\hline & Nitrate & 93.2 & 96.4 & 99.7 \\
\hline & Phosphate & 94.4 & 95.9 & 100.1 \\
\hline & Sulphate & 98.6 & 95.3 & 99.2 \\
\hline \multirow[t]{5}{*}{ Solid waste leaching } & Chloride & 106.8 & 98.1 & 101.5 \\
\hline & Nitrite & 111.9 & 97.1 & 101.5 \\
\hline & Nitrate & 104.3 & 95.6 & 100.3 \\
\hline & Phosphate & 98.5 & 97.4 & 101.3 \\
\hline & Sulphate & 105.3 & 98.5 & 101.4 \\
\hline
\end{tabular}

Low, medium and high range levels correspond to 5.0, 40.0 and $100.0 \mathrm{mg} \mathrm{L}^{-1}$ for phosphate. For the other anions, range levels are 2.5 (low), 20 (medium) and 50 (high) $\mathrm{mg} \mathrm{L}^{-1}$. Italicized values indicate calculations made according to the standard addition method

retention time shifts due to the influence of high ionic strength matrices. Shifts in retention time were reported by other authors testing cleaner matrices (Neele et al. 2002). However, data summarised in Table 6 shows that RSD of retention times was lower than $2 \%$ for all the target anions in all the tested matrices, indicating that retention time shifts did not occur.

Regarding auto-sampler stability, RSD of peak areas ranged from a minimum of $1.2 \%$ (for $\mathrm{PO}_{4}{ }^{3-}$ ) to a maximum of $1.3 \%$ (for $\mathrm{Cl}^{-}$) over the $24 \mathrm{~h}$ the sample was maintained in the autosampler device. RSD of peak areas from the storage stability tests ranged from a 
Table 5 Relative standard deviation of peak areas of $\mathrm{Cl}^{-}, \mathrm{NO}_{2}{ }^{-}, \mathrm{NO}_{3}{ }^{-}, \mathrm{PO}_{4}{ }^{3-}$ and $\mathrm{SO}_{4}{ }^{2-}$ at three different levels of the calibration curve range in five different matrices

\begin{tabular}{|c|c|c|c|c|c|}
\hline Anion & Water & Synthetic sewage & Sewage & Vinasse & Leachate \\
\hline Chloride & $\begin{array}{l}\text { L: } 6.3 \\
\text { M: } 9.2 \\
\text { H: } 5.3\end{array}$ & $\begin{array}{l}\text { L: } 5.5 \\
\text { M: } 1.9 \\
\text { H: } 2.4\end{array}$ & $\begin{array}{l}\text { L: } 6.9 \\
\text { M: } 4.7 \\
\text { H: } 7.7\end{array}$ & $\begin{array}{l}\text { L: } 7.7 \\
\text { M: } 5.8 \\
\text { H: } 3.1\end{array}$ & $\begin{array}{l}\text { L: } 7.9 \\
\text { M: } 3.0 \\
\text { H: } 4.0\end{array}$ \\
\hline Nitrite & $\begin{array}{l}\mathrm{L}: 4.2 \\
\mathrm{M}: 8.5 \\
\mathrm{H}: 5.3\end{array}$ & $\begin{array}{l}\text { L: } 2.6 \\
\text { M: } 2.1 \\
\text { H: } 2.0\end{array}$ & $\begin{array}{l}\mathrm{L}: 8.4 \\
\mathrm{M}: 4.6 \\
\mathrm{H}: 7.3\end{array}$ & $\begin{array}{l}\text { L: } 5.1 \\
\text { M: } 4.7 \\
\text { H: } 3.0\end{array}$ & $\begin{array}{l}\text { L: } 7.8 \\
\text { M: } 3.7 \\
\text { H: } 4.0\end{array}$ \\
\hline Nitrate & $\begin{array}{l}\text { L: } 1.9 \\
\text { M: } 7.9 \\
\text { H: } 5.2\end{array}$ & $\begin{array}{l}\text { L: } 1.3 \\
\text { M: } 1.7 \\
\text { H: } 1.9\end{array}$ & $\begin{array}{l}\mathrm{L}: 4.2 \\
\mathrm{M}: 4.4 \\
\mathrm{H}: 7.4\end{array}$ & $\begin{array}{l}\text { L: } 5.4 \\
\text { M: } 7.5 \\
\text { H: } 2.9\end{array}$ & $\begin{array}{l}\text { L: } 5.3 \\
\text { M: } 2.8 \\
\text { H: } 3.7\end{array}$ \\
\hline Phosphate & $\begin{array}{l}\text { L: } 2.8 \\
\text { M: } 0.8 \\
\text { H: } 5.2\end{array}$ & $\begin{array}{l}\mathrm{L}: 6.4 \\
\mathrm{M}: 2.0 \\
\mathrm{H}: 2.2\end{array}$ & $\begin{array}{l}\mathrm{L}: 4.0 \\
\mathrm{M}: 4.9 \\
\mathrm{H}: 8.2\end{array}$ & $\begin{array}{l}\text { L: } 3.0 \\
\text { M: } 5.0 \\
\text { H: } 3.2\end{array}$ & $\begin{array}{l}\text { L: } 7.5 \\
\text { M: } 3.6 \\
\text { H: } 3.8\end{array}$ \\
\hline Sulphate & $\begin{array}{l}\text { L: } 3.4 \\
\text { M: } 9.9 \\
\text { H: } 5.2\end{array}$ & $\begin{array}{l}\text { L: } 3.2 \\
\text { M: } 2.3 \\
\text { H: } 1.7\end{array}$ & $\begin{array}{l}\text { L: } 5.9 \\
\text { M: } 4.4 \\
\text { H: } 8.2\end{array}$ & $\begin{array}{l}\text { L: } 1.9 \\
\text { M: } 5.1 \\
\text { H: } 2.8\end{array}$ & $\begin{array}{l}\text { L: } 7.1 \\
\text { M: } 3.6 \\
\text { H: } 3.8\end{array}$ \\
\hline
\end{tabular}

$L$ low level, corresponds to $2.5 \mathrm{mg} \mathrm{L}^{-1}$ for $\mathrm{Cl}^{-}, \mathrm{NO}_{2}{ }^{-}, \mathrm{NO}_{3}{ }^{-}$and $\mathrm{SO}_{4}{ }^{2-}$ and to $5.0 \mathrm{mg} \mathrm{L}^{-1}$ for $\mathrm{PO}_{4}{ }^{3-} ; M$ medium level, corresponds to $20.0 \mathrm{mg} \mathrm{L}^{-1}$ for $\mathrm{Cl}^{-}, \mathrm{NO}_{2}^{-}, \mathrm{NO}_{3}{ }^{-}$and $\mathrm{SO}_{4}{ }^{2-}$ and to $40.0 \mathrm{mg} \mathrm{L}^{-1}$ for $\mathrm{PO}_{4}{ }^{3-} ; H$ high level, corresponds to $50.0 \mathrm{mg} \mathrm{L}^{-1}$ for $\mathrm{Cl}^{-}, \mathrm{NO}_{2}{ }^{-}$, $\mathrm{NO}_{3}{ }^{-}$and $\mathrm{SO}_{4}{ }^{2-}$ and to $100.0 \mathrm{mg} \mathrm{L}^{-1}$ for $\mathrm{PO}_{4}{ }^{3-}$

minimum of $1.4 \%$ (for $\mathrm{PO}_{4}{ }^{3-}$ ) to a maximum of $2.0 \%$ (for $\mathrm{SO}_{4}{ }^{2-}$ ).

Linearity, recovery and precision parameters indicate that the method configurations tested are suitable for the analyses of inorganic anions in different types of wastewater as matrix. This might be interesting for laboratories where various complex matrices are monitored, since the maintenance of the same operational conditions save time and labour.

Table 6 Relative standard deviation of retention times of $\mathrm{Cl}^{-}, \mathrm{NO}_{2}{ }^{-}, \mathrm{NO}_{3}{ }^{-}, \mathrm{PO}_{4}{ }^{3-}$ and $\mathrm{SO}_{4}{ }^{2-}$ at three different levels of the calibration curve range in five different matrices

\begin{tabular}{|c|c|c|c|c|c|}
\hline \multirow[t]{2}{*}{ Anion } & \multicolumn{5}{|l|}{ Matrix } \\
\hline & Water & Sewage & Synthetic sewage & Vinasse & Leachate \\
\hline Chloride & $\begin{array}{l}\mathrm{L}: 0.10 \\
\mathrm{M}: 0.03 \\
\mathrm{H}: 0.07\end{array}$ & $\begin{array}{l}\text { L: } 0.06 \\
\text { M: } 0.05 \\
\text { H: } 0.16\end{array}$ & $\begin{array}{l}\text { L: } 0.06 \\
\text { M: } 0.03 \\
\text { H: } 0.00\end{array}$ & $\begin{array}{l}\mathrm{L}: 0.05 \\
\mathrm{M}: 0.05 \\
\mathrm{H}: 0.00\end{array}$ & $\begin{array}{l}\text { L: } 0.06 \\
\text { M: } 0.21 \\
\text { H: } 0.08\end{array}$ \\
\hline Nitrite & $\begin{array}{l}\text { L: } 0.07 \\
\text { M: } 0.07 \\
\text { H: } 0.07\end{array}$ & $\begin{array}{l}\text { L: } 0.04 \\
\text { M: } 0.04 \\
\text { H: } 0.13\end{array}$ & $\begin{array}{l}\text { L: } 0.08 \\
\text { M: } 0.02 \\
\text { H: } 0.02\end{array}$ & $\begin{array}{l}\text { L: } 0.06 \\
\text { M: } 0.02 \\
\text { H: } 0.04\end{array}$ & $\begin{array}{l}\text { L: } 0.04 \\
\text { M: } 0.18 \\
\text { H: } 0.06\end{array}$ \\
\hline Nitrate & $\begin{array}{l}\text { L: } 0.05 \\
\text { M: } 0.08 \\
\text { H: } 0.10\end{array}$ & $\begin{array}{l}\text { L: } 0.05 \\
\text { M: } 0.04 \\
\text { H: } 0.06\end{array}$ & $\begin{array}{l}\text { L: } 0.09 \\
\text { M: } 0.03 \\
\text { H: } 0.04\end{array}$ & $\begin{array}{l}\text { L: } 0.07 \\
\text { M: } 0.04 \\
\text { H: } 0.03\end{array}$ & $\begin{array}{l}\text { L: } 0.04 \\
\text { M: } 0.13 \\
\text { H: } 0.04\end{array}$ \\
\hline Phosphate & $\begin{array}{l}\text { L: } 0.09 \\
\text { M: } 0.11 \\
\text { H: } 0.17\end{array}$ & $\begin{array}{l}\text { L: } 0.07 \\
\text { M: } 0.06 \\
\text { H: } 0.12\end{array}$ & $\begin{array}{l}\text { L: } 0.14 \\
\text { M: } 0.03 \\
\text { H: } 0.07\end{array}$ & $\begin{array}{l}\text { L: } 0.08 \\
\text { M: } 0.06 \\
\text { H: } 0.04\end{array}$ & $\begin{array}{l}\mathrm{L}: 0.06 \\
\mathrm{M}: 0.23 \\
\mathrm{H}: 0.09\end{array}$ \\
\hline Sulphate & $\begin{array}{l}\text { L: } 0.14 \\
\text { M: } 0.15 \\
\text { H: } 0.16\end{array}$ & $\begin{array}{l}\text { L: } 0.06 \\
\text { M: } 0.05 \\
\text { H: } 0.11\end{array}$ & $\begin{array}{l}\text { L: } 0.15 \\
\text { M: } 0.03 \\
\text { H: } 0.06\end{array}$ & $\begin{array}{l}\text { L: } 0.13 \\
\text { M: } 0.04 \\
\text { H: } 0.03\end{array}$ & $\begin{array}{l}\text { L: } 0.07 \\
\text { M: } 0.18 \\
\text { H: } 0.10\end{array}$ \\
\hline
\end{tabular}

$L$ low level, corresponds to $2.5 \mathrm{mg} \mathrm{L}^{-1}$ for $\mathrm{Cl}^{-}, \mathrm{NO}_{2}{ }^{-}, \mathrm{NO}_{3}{ }^{-}$and $\mathrm{SO}_{4}{ }^{2-}$ and to $5.0 \mathrm{mg} \mathrm{L}^{-1}$ for $\mathrm{PO}_{4}{ }^{3-} ; M$ medium level, corresponds to $20.0 \mathrm{mg} \mathrm{L}^{-1}$ for $\mathrm{Cl}^{-}, \mathrm{NO}_{2}{ }^{-}, \mathrm{NO}_{3}{ }^{-}$and $\mathrm{SO}_{4}{ }^{2-}$ and to $40.0 \mathrm{mg} \mathrm{L}^{-1}$ for $\mathrm{PO}_{4}{ }^{3-} ; H$ high level, corresponds to $50.0 \mathrm{mg} \mathrm{L}^{-1}$ for $\mathrm{Cl}^{-}, \mathrm{NO}_{2}{ }^{-}$, $\mathrm{NO}_{3}{ }^{-}$and $\mathrm{SO}_{4}{ }^{2-}$ and to $100.0 \mathrm{mg} \mathrm{L}{ }^{-1}$ for $\mathrm{PO}_{4}{ }^{3-}$ 
Table 7 Matrix effect calculated for domestic wastewater, synthetic sewage, vinasse and leachate

\begin{tabular}{|c|c|c|c|c|}
\hline & Sewage & Synthetic sewage & Vinasse & Leachate \\
\hline Chloride & $-7.4 \%$ & $-25.7 \%$ & $-11.7 \%$ & $-33.9 \%$ \\
\hline Nitrite & $-4.8 \%$ & $-12.8 \%$ & $-1.7 \%$ & $-20.6 \%$ \\
\hline Nitrate & $-3.4 \%$ & $-12.7 \%$ & $-2.6 \%$ & $-19.5 \%$ \\
\hline Phosphate & $-5.1 \%$ & $-16.3 \%$ & $-4.7 \%$ & $-22.4 \%$ \\
\hline Sulphate & $-2.7 \%$ & $-11.9 \%$ & $-5.7 \%$ & $-17.4 \%$ \\
\hline
\end{tabular}

In bold, medium matrix effect

\subsection{Matrix Effect}

A signal enhancement was observed for all the tested matrices and all the anions. The matrix effect level varied from $-1.7 \%$ (nitrite in vinasse) to $-33.9 \%$ (chloride in leachate) (Table 7). Chloride was the anion which showed the highest matrix effect for all the tested matrices, while leachate was the matrix which showed the highest matrix effect for all the tested anions. Overall, nitrate was the anion least affected by the matrix effect and sewage was the matrix which showed the least matrix effect for the tested analytes.

Although vinasse was the matrix which presented the highest electrical conductivity (Table 1), it was not the matrix which gave higher matrix effect. For vinasse, the higher matrix effects were observed for chloride, but still in the range considered as a low matrix effect. In fact, it seems that alkalinity has a higher impact over the equipment response. Comparing the observed response for leachate and vinasse (since the same dilution rate was applied for both matrices), the former presents higher alkalinity, while its electrical conductivity was lower. The observed matrix effects were higher for leachate in all the tested anions (Table 7).

We expected the matrix effect of sewage and synthetic sewage to be similar since the latter aims to mimic the former. The higher matrix effect for synthetic sewage is probably related to the chemical compounds added to the mimic sewage composition. The protocol for this lab-made wastewater (Camiloti et al. 2013) requires the addition of $\mathrm{NaHCO}_{3}$, as a source of alkalinity. The addition of $\mathrm{HCO}_{3}{ }^{-}$could explain the higher matrix effect when compared with sewage. It is likely that carbonates influence the signal response, since the eluent is a carbonate-based solution.

These results indicate that simple dilution is an effective procedure to inorganic anion analyses of high ionic strength matrices (Neele et al. 2002). Moreover, our study is in accordance with Michalski et al. (2012), who reported that analytical columns with high exchange capacity are suitable for the analysis of complex matrices.

\subsection{Anion Profile in the Tested Matrices}

Some of the tested matrices contained the target anions. In such cases, the addition standard method was applied, as previously mentioned. Table 8 shows that the anion concentration calculated in case the analyte was present in the matrix. The confidence limits varied from $7.75 \%$ (chloride for domestic sewage) to $12.5 \%$ (sulphate for vinasse). In almost all cases, the observed concentrations are within the range described in the literature (Table 1), although the waste characterisation in the references mentioned earlier used methods other than IC. The exception was nitrite in leachate. This anion is usually not present in leachate samples (Table 1), but it was observed in our sample. Leachate was collected from landfill and kept without refrigeration for a few days before it was used for validation procedures, providing conditions for partial ammonia oxidation occurrence. Nonetheless, in most cases, the anion concentrations for the analytes which are present in some matrices are followed with the expected values, which hint on favour of the described method.

Table 8 Inorganic anion concentration in case the analyte was present in the matrix

\begin{tabular}{|c|c|c|c|c|}
\hline Anion & Synthetic wastewater & Domestic sewage & Vinasse & Leachate \\
\hline Chloride (mg L ${ }^{-1}$ ) & $130 \pm 16$ & $21.9 \pm 1.7$ & $809 \pm 62.5$ & $1320 \pm 145$ \\
\hline Nitrite $\left(\mathrm{mg} \mathrm{L}^{-1}\right)$ & ND & ND & ND & $270 \pm 32$ \\
\hline Sulphate $\left(\mathrm{mg} \mathrm{L}^{-1}\right)$ & ND & ND & $1021 \pm 12.8$ & ND \\
\hline
\end{tabular}

ND non-detected 


\section{Applications}

The IC method described in this paper has been used to determine anions concentrations for all the tested matrices previously described. One application was nitrite and nitrate removal monitoring in a continuous upflow structured-bed reactor subjected to recirculation and intermittent aeration (SBRRIA) (Santos et al. 2016). The SBRRIA was fed with synthetic wastewater similar to sewage. The authors aimed to study the influence of $\mathrm{COD} / \mathrm{N}$ ration on the simultaneous nitrogen and carbon removal process. They concluded that the system achieved acceptable removal efficiencies of organic matter and nitrogen. Nitrogen removal was achieved through the integration of nitrification, heterotrophic denitrification and anammox processes (Santos et al. 2016).

Another application of the IC method was to investigate sulphur recovery in an Internal Silicone Membrane Reactor (ISMR). Valdés et al. (2016) studied an innovative microaerobic reactor configuration with bubble-free aeration, aiming to recovery elemental sulphur. The ISMR was fed with synthetic sewage, and sodium sulphate $\left(\mathrm{Na}_{2} \mathrm{SO}_{4}\right)$ was added. IC method was used to monitor sulphate concentrations in the system.

IC was used to assess the influence of sulphate on COD removal and methane production using sugarcane vinasse as feedstock (Kiyuna et al. 2017). Sulphate is one of the main interfering compounds on anaerobic digestion and is present in sugarcane vinasse. Distilleries usually add sulphuric acid to prevent microbial contamination and enhance fermentation control in ethanol production (Fuess and Garcia 2015). Hence, vinasse, which is the wastewater generated in ethanol production, is sulphate-rich. A study carried out by Kiyuna et al. (2017) shed light on the influence of this anion in energy recovery.

The IC method was also used in nitrite and nitrate monitoring of an effluent of leachate nitrification. Martins et al. (2017) evaluated the ammonium adsorption in zeolites and its regeneration via nitrification. The authors concluded that nitrite was the main product of regeneration, hinting that anammox-based processes could be used further to achieve complete nitrogen removal from leachate.

Therefore, the anion analysis via the IC method presented was effective for monitoring various bio-processes, targeting both wastewater treatment and the recovery of energy and products.

\section{Conclusions}

The matrix-effect assessment showed that IC is efficient and reliable for inorganic anion analyses in different types of wastewaters using a simple dilution and filtration as sample preparation. Since operational conditions were the same for all the tested matrices, this method seems to be a good option for multi-elemental analyses in various high-ionic wastewaters, allowing to save time and labour. This method was successfully used to monitor inorganic anions found in complex wastewater samples and can be utilised for bioreactor monitoring.

Acknowledgements The authors acknowledge the Fundação de Amparo à Pesquisa no Estado de São Paulo (FAPESP 2009/15984-0) and Professor Marcelo Zaiat for his kind suggestions.

\section{Compliance with Ethical Standards}

Conflict of interest The authors declare that they do not have any conflict of interest.

\section{References}

APHA. Standard Methods for the Examination of Water and Wastewater. 20 th edit ed. [s.1.] American Public Health Association, American Water Works Association, Water Environment Federation, 2005.

Araujo, P. (2009). Key aspects of analytical method validation and linearity evaluation. Journal of Chromatography B: Analytical Technologies in the Biomedical and Life Sciences, 877(23), 2224-2234. https://doi.org/10.1016/j. jchromb.2008.09.030.

Camiloti, P. R., Mockaitis, G., Rodrigues, J. A. D., Damianovic, M. H. R. Z., Foresti, E., \& Zaiat, M. (2013). Innovative anaerobic bioreactor with fixed-structured bed (ABFSB) for simultaneous sulfate reduction and organic matter removal. Journal of Chemical Technology and Biotechnology, 89(7), 1044-1050. https://doi.org/10.1002/jctb.4199.

Camiloti, P. R., Oliveira, G. H. D., \& Zaiat, M. (2016). Sulfur recovery from wastewater using a micro-aerobic external silicone membrane reactor (ESMR). Water, Air and Soil Pollution., 227(1). https://doi.org/10.1007/s11270-0152721-y.

Chiu, Y. C., Lee, L. L., Chang, C. N., \& Chao, A. C. (2007). Control of carbon and ammonium ratio for simultaneous nitrification and denitrification in a sequencing batch bioreactor. International Biodeterioration Biodegradation, 59(1), 1-7. https://doi.org/10.1016/j.ibiod.2006.08.001.

Christofoletti, C. A., Escher, J. P., Correia, J. E., Marinho, J. F. U., \& Fontanetti, C. S. (2013). Sugarcane vinasse: environmental 
implications of its use. Waste Management, 33(12), 27522761. https://doi.org/10.1016/j.wasman.2013.09.005.

Economou, A., Botitsi, H., Antoniou, S., \& Tsipi, D. (2009). Determination of multi-class pesticides in wines by solidphase extraction and liquid chromatography-tandem mass spectrometry. Journal of Chromatography A, 1216(31), 5856-5867. https://doi.org/10.1016/j.chroma.2009.06.031.

Fuess, L. T., \& Garcia, M. L. (2015). Bioenergy from stillage anaerobic digestion to enhance the energy balance ratio of ethanol production. Journal of Environmental Management, 162, 102-114. https://doi.org/10.1016/j.jenvman.2015.07.046.

Gade, B. (1993). Ion chromatographic investigations of leachates from a hazardous-waste landfill. Journal of Chromatography A, 640-1(2), 227-230. https://doi. org/10.1016/0021-9673(93)80185-B.

García, D., Alcántara, C., Blanco, S., Pérez, R., Bolado, S., \& Muñoz, R. (2017). Enhanced carbon, nitrogen and phosphorus removal from domestic wastewater in a novel anoxicaerobic photobioreactor coupled with biogas upgrading. Chemical Engineering Journal, 313, 424-434. https://doi. org/10.1016/j.cej.2016.12.054.

Jackson, L. K., Joyce, R. J., Laikhtman, M., \& Jackson, P. E. (1998). Determination of trace level bromate in drinking water by direct injection ion chromatography. Journal of Chromatography A, 829-1(2), 187-192. https://doi. org/10.1016/S0021-9673(98)00774-2.

Jackson, P. E. (2006). Ion chromatography in environmental analysis. In Encyclopedia of analytical chemistry (pp. 27792801). Chichester: John Wiley \& Sons Ltd.

Jackson, P. E., Thomas, D. H., Donovan, B., Pohl, C. A., \& Kiser, R. E. (2001). New block-grafted anion exchanger for environmental water analysis by ion chromatography. Journal of Chromatography A, 920(1-2), 51-60. https://doi. org/10.1016/S0021-9673(00)01225-5.

Kiyuna, L. S. M., Fuess, L. T., \& Zaiat, M. (2017). Unraveling the influence of the $\mathrm{COD} /$ sulfate ratio on organic matter removal and methane production from the biodigestion of sugarcane vinasse. Bioresource Technology, 232, 103-112. https://doi. org/10.1016/j.biortech.2017.02.028.

Kjeldsen, P., Barlaz, M. A., Rooker, A. P., Baun, A., Ledin, A., \& Christensen, T. H. (2002). Present and long-term composition of MSW landfill leachate: A review. Critical Reviews in Environmental Science and Technology, 32(4), 297-336. https://doi.org/10.1080/10643380290813462.

Kruve, A., Rebane, R., Kipper, K., Oldekop, M. L., Evard, H., Herodes, K., Ravio, P., \& Leito, I. (2015). Tutorial review on validation of liquid chromatography-mass spectrometry methods: part I. Analytica Chimica Acta, 870(1), 8-28. https://doi.org/10.1016/j.aca.2015.02.017.

Lacerda, C. V., Ritter, E., Costa Pires, J. A., \& Castro, J. A. (2014). Migration of inorganic ions from the leachate of the Rio Das Ostras landfill: a comparison of three different configurations of protective barriers. Waste Management, 34(11), 22852291. https://doi.org/10.1016/j.wasman.2014.06.012.

Lopez-Moreno, C., Viera, I., \& Urbano, A. M. (2010). Validation of an ion chromatographic method for the quantification of anions in water. Desalination, 261(1-2), 111-116. https://doi. org/10.1016/j.desal.2010.05.022.

Martins, T. H., Souza, T. S. O., \& Foresti, E. (2017). Ammonium removal from landfill leachate by Clinoptilolite adsorption followed by bioregeneration. Journal of Environmental
Chemical Engineering., 5, 63-68. https://doi.org/10.1016/j. jece.2016.11.024.

Matuszewski, B. K., Constanzer, M. L., \& Chavez-Eng, C. M. (2003). Strategies for the assessment of matrix effect in quantitative bioanalytical methods based on HPLC-MS/MS. Analytical Chemistry, 75(13), 3019-3030 https://doi. org/10.1021/ac020361s.

Michalski, R. (2006). Ion chromatography as a reference method for determination of inorganic ions in water and wastewater. Critical Reviews in Analytical Chemistry, 36(Sep), 107-127.

Michalski, R., Lyko, A., \& Kurzyca, I. (2012). Matrix influences on the determination of common ions by using ion chromatography part 1 - determination of inorganic anions. Journal of Chromatographic Science, 50(6), 482-493. https://doi. org/10.1093/chromsci/bms027.

Miller JM, Miller JC (2010) Statistics and Chemometrics for Analytical Chemistry. $6^{\text {th }}$ ed.: Pearson Education Limited, Essex, England.

Miskaki, P., Lytras, E., Kousouris, L., \& Tzoumerkas, P. (2007). Data quality in water analysis: validation of ion chromatographic method for the determination of routine ions in potable water. Desalination, 213(1-3), 182-188. https://doi. org/10.1016/j.desal.2006.05.063.

Moraes, B. S., Zaiat, M., \& Bonomi, A. (2015). Anaerobic digestion of vinasse from sugarcane ethanol production in Brazil: challenges and perspectives. Renewable and Sustainable Energy Reviews, 44, 888-903. https://doi.org/10.1016/j. rser.2015.01.023.

Moura, R. B., Damianovic, M. H. R. Z., \& Foresti, E. (2012). Nitrogen and carbon removal from synthetic wastewater in a vertical structured-bed reactor under intermittent aeration. Journal of Environmental Management, 98, 163-167. https://doi.org/10.1016/j.jenvman.2012.01.009.

Naveen, B. P., Mahapatra, D. M., Sitharam, T. G., Sivapullaiah, P. V., \& Ramachandra, T. V. (2016). Physico-chemical and biological characterization of urban municipal landfill leachate. Environmental Pollution, 220, 1-12. https://doi. org/10.1016/j.envpol.2016.09.002.

Neele, J., Cleven, R., \& Van De Wiel, H. (2002). Matrix effects in the determination of low anion concentrations using suppressed IC. International Journal of Environmental Analytical Chemistry, 82(1), 13-22. https://doi.org/10.1080 103067310290024058.

Paull, B., \& Nesterenko, P. (2005). Novel ion chromatographic stationary phases for the analysis of complex matrices. Analyst, 130(2), 134-146. https://doi.org/10.1039/B406355B.

Philips, S., Laanbroek, H. J., \& Verstraete, W. (2002). Origin, causes and effects of increased nitrite concentrations in aquatic environments. Reviews in Environmental Science and Biotechnology, 1, 115-141. https://doi.org/10.1023/A:1020892826575.

Poggi-Varaldo, H. M., Munoz-Paez, K. M., Escamilla-Alvarado, C., et al. (2014). Biohydrogen, biomethane and bioelectricity as crucial components of biorefinery of organic wastes: a review. Waste Management and Research, 32(5), 353-365. https://doi.org/10.1177/0734242X14529178.

Santos, C. E. D., Moura, R. B., Damianovic, M. H. R. Z., \& Foresti, E. (2016) Influence of $\mathrm{COD} / \mathrm{N}$ ratio and carbon source on nitrogen removal in a structured-bed reactor subjected to recirculation and intermittent aeration (SBRRIA). Journal of Environmental Management 166,519-524. https://doi.org/10.1016/j.jenvman.2015.10.054. 
Santos, J. D., Silva, A. L. L., Costa, J. L., Scheidt, G. N., Novak, A. C., Sydney, E. B., \& Soccol, C. R. (2013). Development of a vinasse nutritive solution for hydroponics. Journal of Environmental Management, 114, 8-12. https://doi. org/10.1016/j.jenvman.2012.10.045.

Singh, R. P., Abbas, N. M., \& Smesko, S. A. (1996). Suppressed ion chromatographic analysis of anions in environmental waters containing high salt concentrations. Journal of Chromatography A, 733(1-2), 73-91. https://doi. org/10.1016/0021-9673(95)00957-4.

Tchobanoglous, G., Burton, F. L., \& Stensel, H. D. (2003). Metcalf $\&$ Eddy: Wastewater engineering, treatment and reuse (4th ed.). New York: McGraw Hill Education.

Thompson, M., Ellison, S. L. R., \& Wood, R. (2002). Harmonized guidelines for single-laboratory validation of methods of analysis (IUPAC Technical Report). Pure Applied Chemistry, 74(5), 835-855.
USEPA.(1993) Method 300.1-1 - Determination of inorganic anions in drinking water by ion chromatography. Cincinnati, $\mathrm{OH}$.

Valdés, F., Camiloti, P. R., Rodriguez, R. P., Delforno, T. P., Carrillo-Reyes, J., \& Zaiat, M. D. (2016). Sulfide-oxidizing bacteria establishment in an innovative microaerobic reactor with an internal silicone membrane for sulfur recovery from wastewater. Biodegradation, 27, 119-130.

Villagrán, C., Deetlefs, M., Pitner, R. W., \& Hardacre, C. (2004). Quantification of halide in ionic liquids using ion chromatography. Analytical Chemistry, 76(7), 2118-2123. https://doi.org/10.1007/s10532-016-9760-y.

Von Sperling, M. (2007). Wastewater characteristics, treatment and disposal. London: IWA Publishing. 